Regards sur l'économie allemande

Bulletin économique du CIRAC

82 | 2007

Varia

\title{
Philosophie politique
}

HACKE Jens, Philosophie der Bürgerlichkeit. Die liberalkonservative Begründung der Bundesrepublik

\section{(2) OpenEdition}

\section{Journals}

Édition électronique

URL : http://journals.openedition.org/rea/435

DOI : $10.4000 /$ rea. 435

ISBN : 978-2-8218-0860-7

ISSN : 1965-0787

Éditeur

CIRAC

Édition imprimée

Date de publication : 1 juillet 2007

ISSN : 1156-8992

Référence électronique

«Philosophie politique », Regards sur l'économie allemande [En ligne], 82 I juillet 2007, document 4, mis en ligne le 23 avril 2008, consulté le 22 septembre 2020. URL : http://journals.openedition.org/rea/435 ; DOI : https://doi.org/10.4000/rea.435

Ce document a été généré automatiquement le 22 septembre 2020

(C) CIRAC 


\title{
Philosophie politique
}

\author{
HACKE Jens, Philosophie der Bürgerlichkeit. Die liberalkonservative \\ Begründung der Bundesrepublik
}

\section{RÉFÉRENCE}

HACKE Jens, Philosophie der Bürgerlichkeit. Die liberalkonservative Begründung

der Bundesrepublik, Vandenhoeck \& Ruprecht, Göttingen, 2006, 324 p.

1 L' «ordre constitutionnel libéral et démocratique », cet équilibre entre liberté et responsabilité, entre intérêts particulier et collectif, entre concurrence et solidarité, entre économie et marché, qui fonde l'organisation de l'économie et de la société allemandes ne s'est pas imposé aussi naturellement qu'ont croit et ne procède en rien d'un 'miracle politique'. La doctrine d'un Ludwig Erhard qui en est l'un des pères fondateurs, et qui se justifiait aisément dans un pays en ruines dont il fallait d'abord reconstruire l'économie avant de songer à partager les richesses produites au fur et à mesure que le marché se remettait à fonctionner, s'est trouvée soumise à de très vives critiques au cours des années 1960/70 - une fois le " miracle économique » assis sur des bases solides -, émanant de tous horizons, mais particulièrement virulentes à gauche. Des intellectuels comme Jürgen Habermas partaient alors en guerre contre ce « système post-capitaliste ", d'autres contre le "régime adenauerien ", mettant en cause ces valeurs « bourgeoises » sur lequel il reposerait. Mais petit à petit, le consensus a fini par se construire sur ce libéralisme organisé qui caractérise le "capitalisme rhénan ", grâce notamment à l'apport de penseurs libéraux comme Odo Marquard ou issus de l'école de Joachim Ritter à Munster (Westphalie). C'est ce processus que décrit le présent ouvrage, issu d'une thèse de philosophie soutenue en 2004 à l'Université Humboldt de Berlin, et dont l'auteur a recueilli les témoignages de protagonistes comme les professeurs Hermann Lübbe ou Odo Marquard. (ib) 